\title{
In Vivo Activation of Channelrhodopsin-2 Reveals That Normal Patterns of Spontaneous Activity Are Required for Motoneuron Guidance and Maintenance of Guidance Molecules
}

\author{
Ksenia V. Kastanenka and Lynn T. Landmesser \\ Department of Neurosciences, Case Western Reserve University, School of Medicine, Cleveland, Ohio 44106-4975
}

\begin{abstract}
Spontaneous, highly rhythmic episodes of propagating bursting activity are present early during the development of chick and mouse spinal cords. Acetylcholine, and GABA and glycine, which are both excitatory at this stage, provide the excitatory drive. It was previously shown that a moderate decrease in the frequency of bursting activity, caused by in ovo application of the $\mathrm{GABA}_{\mathrm{A}}$ receptor blocker, picrotoxin, resulted in motoneurons making dorsal-ventral (D-V) pathfinding errors in the limb and in the altered expression of guidance molecules associated with this decision. To distinguish whether the pathfinding errors were caused by perturbation of the normal frequency of bursting activity or interference with $\mathrm{GABA}_{\mathrm{A}}$ receptor signaling, chick embryos were chronically treated in ovo with picrotoxin to block $\mathrm{GABA}_{\mathrm{A}}$ receptors, while light activation by channelrhodopsin-2 was used to restore bursting activity to the control frequency. The restoration of normal patterns of neural activity in the presence of picrotoxin prevented the $\mathrm{D}-\mathrm{V}$ pathfinding errors in the limb and maintained the normal expression levels of EphA4, EphB1, and polysialic acid on neural cell adhesion molecule, three molecules previously shown to be necessary for this pathfinding choice. These observations demonstrate that developing spinal motor circuits are highly sensitive to the precise frequency and pattern of spontaneous activity, and that any drugs that alter this activity could result in developmental defects.
\end{abstract}

\section{Introduction}

Early during development, as motoneurons are pathfinding to their muscle targets, they establish connections with other motoneurons and interneurons in the spinal cord. Such connections result in the assembly of functionally active spinal circuits. As early as embryonic day 4 (E4) (chick) or E11.5-12 (mouse), just as their axons have exited the spinal cord and fasciculated into muscle-specific fascicles, and while their somas are still migrating, lumbar motoneurons exhibit highly rhythmic spontaneous bursts of propagating electrical activity (Milner et al., 1999; Hanson and Landmesser, 2003). The activity propagates in the form of waves (O'Donovan et al., 2005) and in chicks has been shown to originate in the upper cervical spinal cord (Momose-Sato et al., 2009). Cholinergic neurotransmission is critical for generating these spontaneous waves, while GABA and glycine also contribute to the excitatory drive (Milner et al., 1999; Hanson and Landmesser, 2003).

Received June 1, 2010; accepted June 24, 2010.

This work was supported by National Institutes of Health Grant NS19640. We thank Maryanne Pendergast and the Neurosciences Imaging Center for assistance with the confocal microscopy. We thank William Frank for help in constructing the light activation apparatus, and Susann Brady-Kalnay for comments on the manuscript. The Islet1 and Lim1 antibodies were obtained from the Developmental Studies Hybridoma Bank, which is operated under the auspices of the National Institute of Childhood Health and Human Development and is maintained by the Department of Biology at the University of lowa.

Correspondence should be addressed to Lynn T. Landmesser, Department of Neurosciences, Case Western Reserve University, 10900 Euclid Avenue, Cleveland, OH 44106-4975. E-mail: Iynn.landmesser@case.edu.

DOI:10.1523/JNEUROSCI.2773-10.2010

Copyright $\odot 2010$ the authors $\quad 0270-6474 / 10 / 3010575-11 \$ 15.00 / 0$
Decreasing the frequency of rhythmic bursting activity with the in ovo application of the $\mathrm{GABA}_{\mathrm{A}}$ antagonist, picrotoxin, resulted in dorsal-ventral (D-V) pathfinding errors as well as a decrease in the levels of the EphA4 receptor and of polysialic acid (PSA) on neural cell adhesion molecule (NCAM) on motoneuron axons at the D-V choice point (Hanson and Landmesser, 2004). Normally, EphA4-positive growth cones of dorsally projecting motoneurons are repelled by Ephrin As in ventral mesenchyme (Eberhart et al., 2002; Kania and Jessell, 2003), whereas the EphB1-bearing growth cones of ventrally projecting motoneurons are repelled by Ephrin Bs in dorsal mesenchyme (Luria et al., 2008). In contrast, modest increases in the frequency of bursting activity produced by the glycine uptake inhibitor sarcosine did not perturb D-V pathfinding but resulted in pool-specific pathfinding errors (Hanson and Landmesser, 2006). Together, these studies suggested that modest alterations in the normal frequency of neural activity differentially perturbed the two major pathfinding decisions made by motoneurons. However, it was unclear whether alterations in the frequency of rhythmic depolarizations and downstream calcium signaling, or in signaling via $G_{A B A}$ receptors, caused the pathfinding errors, since picrotoxin, used to decrease the frequency of bursting episodes, also blocked $\mathrm{GABA}_{\mathrm{A}}$ receptors. GABA has in fact been shown to play multiple roles in developmental processes, such as cell proliferation, migration, and survival (Owens and Kriegstein, 2002; Represa and Ben-Ari, 2005). To distinguish between these possibilities, we activated the motor circuit at normal bursting frequencies by light activation 
by channelrhodopsin-2 (ChR2) in the presence of picrotoxin. $\mathrm{Li}$ et al. (2005) showed that after in ovo electroporation in chicks, ChR2 could be used to drive bursting activity both in isolated spinal cord preparations and in intact embryos. We show here that driving activity at the normal frequency with ChR2 in the presence of the $\mathrm{GABA}_{\mathrm{A}}$ blocker picrotoxin prevented the $\mathrm{D}-\mathrm{V}$ pathfinding errors and restored the normal levels of PSA, EphA4, and EphB1 on motoneuron axons. Our results indicate that the normal frequency of bursting activity, and not $\mathrm{GABA}_{\mathrm{A}}$ signaling, is required for accurate $\mathrm{D}-\mathrm{V}$ pathfinding, and suggest that this is because activity is required to maintain the normal levels of EphA4, EphB1, and PSA, enabling axons to reach their proper $\mathrm{D}-\mathrm{V}$ targets.

\section{Materials and Methods}

Chronic drug treatments. White leghorn chicken embryos were incubated until stage (St) 18. At that stage, a square hole was made in the shell, surrounded by a lip of paraffin and sealed with a glass coverslip. Starting at St 20, embryos in the chronic picrotoxin treatment were treated with the $\mathrm{GABA}_{\mathrm{A}}$ receptor antagonist picrotoxin through the window in the shell. Twice a day, at $12 \mathrm{~h}$ intervals, picrotoxin $(0.1 \mathrm{mg} / \mathrm{d})$ dissolved in sterile chick tyrode was administered through the pipette until St 25-27.

Light activation by ChR2. A ChR2 DNA construct containing an enhanced green fluorescent protein (eGFP) under the cytomegalovirus (CMV) promoter $(5 \mu \mathrm{g} / \mu \mathrm{l}$; a gift from Stefan Herlitze, Case Western Reserve University, Cleveland, OH) (Li et al., 2005) was introduced into the upper cervical central canal of St 18 chicken embryos and electroporated into one side of the upper cervical spinal cord. Embryos were incubated in a specially constructed incubator that prevented ambient light from entering and had implanted light guides to supply flashes of light at desired frequencies. Starting at St 20, embryos were treated with picrotoxin, as described above, as well as stimulated with brief flashes of white light ( $1 \mathrm{~s}$ in duration) that activated ChR2 every $40 \mathrm{~s}$, the control frequency, until St 25-27. Some ChR2-electroporated embryos were also activated with light at intervals of $20 \mathrm{~s}$, at twice the control frequency, in the absence of picrotoxin. In both cases, in ovo movements were quantified to ensure that the desired frequency was maintained during the chronic stimulation.

Quantification of in ovo movements. To quantify the intervals between in ovo movements, the embryos were videotaped with a digital camera (MagnaFire, Olympus America) through the square window in the shell. For the duration of video recording, embryos were warmed to $38-40^{\circ} \mathrm{C}$ with a heating pad. Subsequently, time intervals between episodes of activity were recorded as intervals between the S-shaped axial movements as early as St 23 or 25 . Previous studies with isolated cord preparations demonstrated that every episode of activity recorded electrically from a spinal nerve was associated with an S-shaped movement caused by sequential activation of axial muscles, which are activated at stages when limb-innervating axons are still growing to their muscle targets (Milner and Landmesser, 1999; Hanson and Landmesser, 2004). An episode consisted of one or more axial movements. Each embryo was recorded one or two times. Embryos electroporated with ChR2 were recorded in red light $(620 \mathrm{~nm})$, which does not activate ChR2. ChR2 was activated with brief flashes of white light at specified intervals, and intermovement intervals between the flashes were recorded. Intermovement intervals were averaged and compared between conditions.

Retrograde labeling of motoneurons with horseradish peroxidase. After a ventral laminectomy, the dorsal or ventral nerve trunks of embryos were injected with 10\% horseradish peroxidase (HRP) (Invitrogen) in isolated spinal cord-hindlimb preparations and incubated for $6 \mathrm{~h}$ at $32^{\circ} \mathrm{C}$ in oxygenated Tyrodes solution to allow for retrograde transport to the cell bodies in the spinal cords.

Subsequently, limbs and spinal cords were fixed in $3.7 \%$ formaldehyde in a PBS solution for $30 \mathrm{~min}$, washed, and cryoprotected in 30\% sucrose overnight at $4^{\circ} \mathrm{C}$. Limbs and spinal cords were mounted in a 1:1 mixture of $60 \%$ sucrose and tissue-freezing medium (Triangle Biomedical Sciences) separately, frozen on dry ice-cooled isopentane, and cryostat sectioned at $-26^{\circ} \mathrm{C}$ at a thickness of $16 \mu \mathrm{m}$ (Cryocut 1800, Leica).
Immunohistochemistry. Sixteen micrometer transverse sections of lumbar level spinal cord were incubated with antibodies against HRP (rabbit anti-HRP, 1:400, Jackson Immunoresearch) and Lim1 [mouse anti-Lim1 4F2 ascides, 1:500, Developmental Studies Hybridoma Bank (DSHB)] or Islet1 (mouse anti-Islet1 3F7 concentrate, 1:50, DSHB). Transverse sections of the limbs were incubated with antibodies against Neurofilament M (NF-M) (mouse anti-NF-M, 1E9, full-strength hybridoma supernatant). This monoclonal antibody was shown to be specific for NF-M (L. Landmesser, unpublished observations) (Hanson and Landmesser, 2004). The sections were also stained with antibodies against EphA4 (rabbit anti-EphA4, 1:500, Zymed Laboratories) or EphB1 (goat anti-EphB1, 1:50, Santa Cruz Biotechnology). Similarly, sections were incubated with antibodies against PSA (5A5, 1:100) and $\operatorname{NCAM}(5 \mathrm{E}, 10 \mu \mathrm{g} / \mathrm{ml})$ (Hanson and Landmesser, 2004) for $2 \mathrm{~h}$ at room temperature. Then, the sections were incubated with appropriate secondary antibodies for $1 \mathrm{~h}$, mounted with ProLong Antifade reagent (Invitrogen), and visualized using an upright Nikon Microphot-FX. Thus, for each molecule, the sections from control, picrotoxin, and picrotoxinplus-light activation were incubated with the same primary and secondary antibodies at the same concentrations and according to the same protocol. In addition, care was taken to first try a range of antibody concentrations for each antibody to select the concentration that enabled one to observe the full range of expression of the molecule it was directed against.

Image acquisition and analysis. Images were captured on an upright Nikon Microphot-FX with a digital camera (MagnaFire, Olympus America) using the QCapture software. For each molecule described in Figures $4-7$, the images for control, picrotoxin, and picrotoxin-plus-light activation were acquired at the same exposure parameters and light intensity to enable appropriate quantification of mean pixel intensities within individual regions of interest. Care was taken to acquire the brightest of the three examples at an exposure within the linear range and thus avoid saturation. Confocal images were acquired with a Zeiss LSM 510 META laser scanning confocal microscope (Carl Zeiss Micro Imaging) using an Argon laser (excitation, $488 \mathrm{~nm}$ ), a HeNe laser (excitation, $543 \mathrm{~nm}$ ), and a multi-immersion $25 \times$ Plan-Neofluar (numerical aperture, 0.8; Ph2) objective.

Quantification of misplaced motoneurons and D-V pathfinding errors. Sixteen micrometer cross sections from the spinal cords of control, chronic picrotoxin, and chronic picrotoxin and light-activated St $27 \mathrm{em}-$ bryos, whose dorsal or ventral nerve trunks had been injected with HRP, were stained with anti-HRP antibodies. For both ventrally and dorsally projecting HRP-injected motoneurons, the number of HRP-positive cell bodies present in a spinal cord location inappropriate for the projection pattern of these motoneurons [cell bodies located in the medial half of the lateral motor column $\left(\mathrm{LMC}_{\mathrm{M}}\right)$ for motoneurons projecting dorsally or cell bodies present in the lateral half of the $\mathrm{LMC}\left(\mathrm{LMC}_{\mathrm{L}}\right)$ for motoneurons projecting ventrally] was expressed as a percentage of all HRPpositive cells present on that side of the spinal cord per $16 \mu \mathrm{m}$ section. The percentages in each condition were averaged and depicted in a bar graph.

To calculate D-V pathfinding errors, $16 \mu \mathrm{m}$ cross sections of St 27 chick spinal cords were stained with antibodies against Lim1 or Islet1 in addition to HRP. Ventrally projecting motoneurons expressing Lim1 and dorsally projecting motoneurons expressing Islet 1 were considered to represent $\mathrm{D}-\mathrm{V}$ pathfinding errors. The number of $\mathrm{D}-\mathrm{V}$ pathfinding errors was shown as a percentage of all HRP-positive cells per $16 \mu \mathrm{m}$ section on one side of the spinal cord. The percentages were averaged and represented in a bar graph under different conditions.

Fluorescence quantification. Images of transverse limb cross sections coimmunostained with EphA4 and NF-M, EphB1 and NCAM, or PSA and NCAM were imported into MetaMorph Imaging Analysis Software (version 7.1.7.0, Universal Imaging). Regions of interest were outlined just distal to the D-V choice point on dorsal nerve trunks on EphA4stained sections, on ventral nerve trunks on EphB1-stained sections, and on both dorsal and ventral nerve trunks on PSA-stained sections. Pixel intensities were calculated in MetaMorph for each of the three molecules and respective background levels were subtracted. The pixel intensities were averaged for each experimental condition and compared among 
A

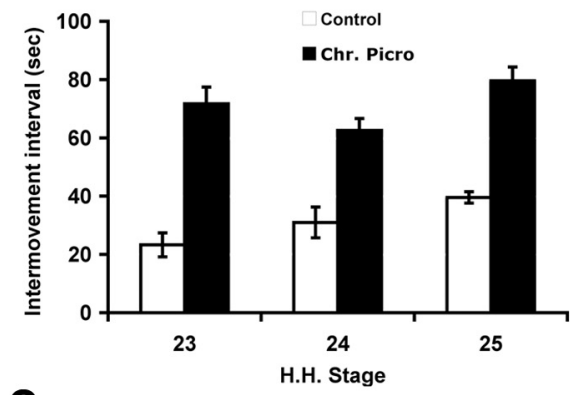

C

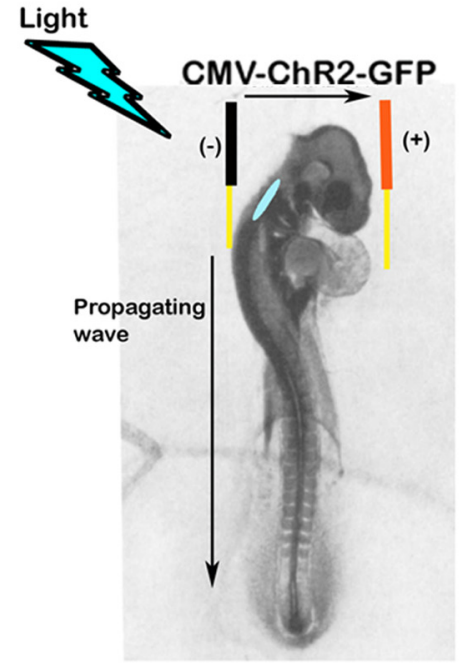

E

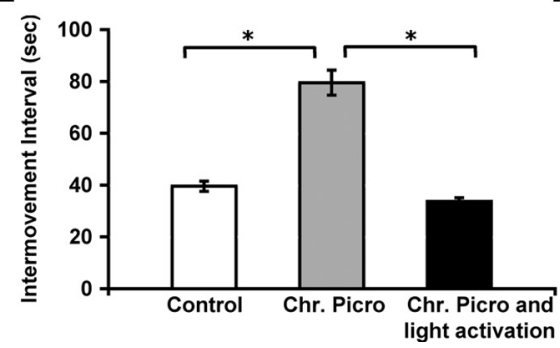

B

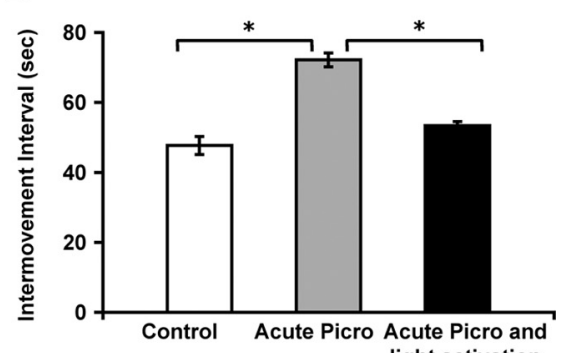

D

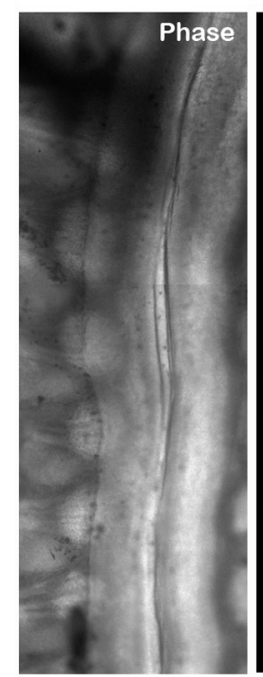

light activation

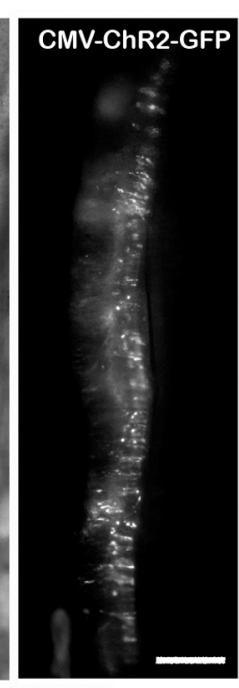

$F$

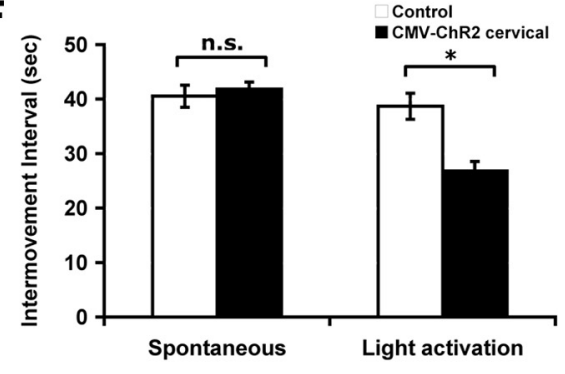

Figure 1. Intervals between episodes of axial movement activity in control, picrotoxin-treated, and picrotoxin together with light activation by ChR2-treated embryos. $\boldsymbol{A}$, Bar graph of intervals between in ovo movements of control and chronic picrotoxintreated embryos at St 23, 24, and 25. Chronic picrotoxin treatment slowed the frequency of bursting activity. $\boldsymbol{B}$, Bar graphs of the intermovement intervals in ovo quantified at St 25 in control embryos, embryos acutely treated with picrotoxin at St 25, and embryos acutely treated with picrotoxin and that had been stimulated with brief flashes of light every $40 s\left({ }^{*} p<0.025\right)$. $\boldsymbol{C}$, Schematic showing the approximate location (blue oval) in the upper cervical spinal cord, where the ChR2-eGFP construct was injected in St 18 chick embryos. Even though the construct was electroporated into one side of the cervical spinal cord, light activation was able to elicit a propagating wave into the lumbar region. D, ChR2- eGFP expression was detected in the spinal cord of St 25 chick. Left, Phase contrast picture of spinal cord whole mount showing cord and DRGs on the left side. Right, Same field as left, showing ChR2 expression on one side of the cord. Rostral is up. Scale bar, $200 \mu \mathrm{m}$. $\boldsymbol{E}$, Intermovement intervals in control, chronic picrotoxin-treated embryos, and embryos treated with picrotoxin but activated with light by ChR2 assessed at St 25 . Chronic picrotoxin treatment slowed the frequency of bursting activity. Light activation by ChR2 in addition to chronic picrotoxin treatment maintained the frequency of bursting activity similar to control values $\left({ }^{*} p<0.025\right)$. $\boldsymbol{F}$, Intermovement intervals were also quantified in control embryos and those electroporated with ChR2. Unless stimulated with brief flashes of light at twice the normal frequency, electroporation of ChR2 had no significant effect on the intermovement interval at St $25\left(^{*} p<0.025\right)$. Chr. Picro, Chronic picrotoxin treatment.

control, chronic picrotoxin, and chronic picrotoxin with light activation by ChR2-treated embryos.

Alterations in the packing density or fasciculation of axons in different regions or sections would influence the pixel intensity of immunostaining. To correct for variations in axonal packing density, we determined pixel intensities for NF-M fluorescence using the regions of interest used to quantify EphA4 fluorescence, or NCAM fluorescence with the regions of interest used to quantify EphB1 fluorescence, or NCAM fluorescence, for the regions of interest used to quantify PSA fluorescence. Thus, the regions of interest that were previously saved in EphA4, EphB1, and PSA channels were loaded into NF-M and NCAM channels for the same sections, pixel intensities for those were recorded, and background levels subtracted. Pixel intensities with background subtracted were averaged for control, chronic picrotoxin, and chronic picrotoxin plus light activation by ChR 2 conditions. The averages for pixel intensities for NF-M-stained sections, coimmunostained with EphA4, were comparable to the different treatments, as were the averages for pixel intensities for NCAM coimmunostained with EphB1 or PSA. This result also confirms the data published previously (Hanson and Landmesser, 2004), which showed that the expression of neither NF-M nor NCAM were altered as a result of chronic picrotoxin treatment.

To quantify the intensity of Lim 1 or Islet 1 immunostaining, transverse spinal cord sections from St 27 chick embryos that were not treated, chronically treated with picrotoxin, or treated chronically with picrotoxin but simultaneously activated at control bursting frequencies with ChR2 were stained as described above. The intensity of immunostaining in regions of interest consisting of either the lateral or medial portion of the LMC were then quantified as mean pixel intensity, and the different treatments compared.

Statistical significance was determined using ANOVA. Bonferroni correction of $p$ values was used when multiple comparisons were made, as follows. The fluorescence intensity of EphA4 or EphB1 was compared on dorsal or ventral nerve trunks, respectively, between control and chronic picrotoxin-treated embryos or chronic picrotoxin-treated embryos and embryos treated with light activation by ChR2 and picrotoxin, thus comprising two comparisons. To consider the two comparisons, a $p$ value of 0.05 was corrected to 0.025 . A $p$ value of 0.025 was also used to compare PSA fluorescence intensities between conditions.

\section{Results}

In ovo electroporated ChR2 can be used to drive neural activity at the normal frequency in the presence of picrotoxin during in vivo motoneuron axon outgrowth

To test whether the normal frequency of bursting activity or $\mathrm{GABA}_{\mathrm{A}}$ signaling is necessary for proper pathfinding of motoneurons in picrotoxin-treated embryos, it was first necessary to verify that light activation by ChR2 could drive bursting activity at normal levels in picrotoxin-treated embryos where $\mathrm{GABA}_{\mathrm{A}}$ receptors were blocked. Acute application of picrotoxin $(50 \mu \mathrm{M})$ has been shown to slow the frequency of bursting activity in isolated spinal cord preparations (Hanson and Landmesser, 2004). Picrotoxin ( $0.05 \mathrm{mg}$ in $100 \mu \mathrm{l}$ of Tyrodes solution) also slowed bursting frequency when applied acutely or chronically each 
day in ovo (Hanson and Landmesser, 2004). Although limb muscles have not yet formed by St 23-25, when motoneurons are making the $\mathrm{D}-\mathrm{V}$ pathfinding decision at the base of the limb, axial muscles are innervated and each wave of electrical activity generates an axial movement that can be observed through a window in the shell (see Materials and Methods for additional details). This enabled us to confirm that chronic picrotoxin treatment increased the interval between axial movements throughout the period of the $\mathrm{D}-\mathrm{V}$ pathfinding choice. This was important since homeostatic changes can occur to restore activity in developing cord circuits when activity is perturbed (Chub and O'Donovan, 1998; Milner and Landmesser, 1999; Gonzalez-Islas and Wenner, 2006). Figure $1 A$ shows that picrotoxin increased the interval between axial movements by a factor of 2-3 throughout this period. We next showed that when picrotoxin was applied acutely to St 25 embryos, which had been electroporated with ChR2 at St 18, that the interval between movements was increased by a similar amount in the absence of light. However, brief flashes of light every $40 \mathrm{~s}$ were able to restore the intermovement intervals to control levels in the presence of picrotoxin (Fig. $1 \mathrm{~B}$ ).

The $\mathrm{D}-\mathrm{V}$ pathfinding decision in chick embryos is executed between St 23 and St 25 (Lance-Jones and Landmesser, 1981a). Thus, it was necessary to be able to maintain the normal frequency of bursting activity with light activation by ChR2 in picrotoxin-treated embryos throughout these stages. To determine whether chronic activation of ChR2 could drive movements with the control frequency until St 25 , when the $\mathrm{D}-\mathrm{V}$ pathfinding decision has been executed, embryos were electroporated with ChR2 at St 18, and flashes of light were applied every $40 \mathrm{~s}$ from St 20 to St 25. Axial movements in ovo and spontaneous electrical bursts in isolated cord preparations first become evident at $\mathrm{St}$ 23. However, since spontaneous activity might occur at even earlier stages we began our light treatment at St 20. ChR2 was electroporated into the upper cervical spinal cords (Fig. 1C) because at these early stages (St 23-25) the waves of spontaneous activity arise in this region and propagate caudally to activate the lumbar cord (Momose-Sato et al., 2009). This site of ChR2 expression also avoided any possibly deleterious effects of expressing and activating ChR2 chronically in the motoneurons we were studying. The ChR2-eGFP construct was under the control of the CMV promoter and was the same one used in a previous study (Li et al., 2005), which showed that it could be expressed at lumbar and brachial levels in both motoneurons and interneurons and was capable of acutely driv-

E
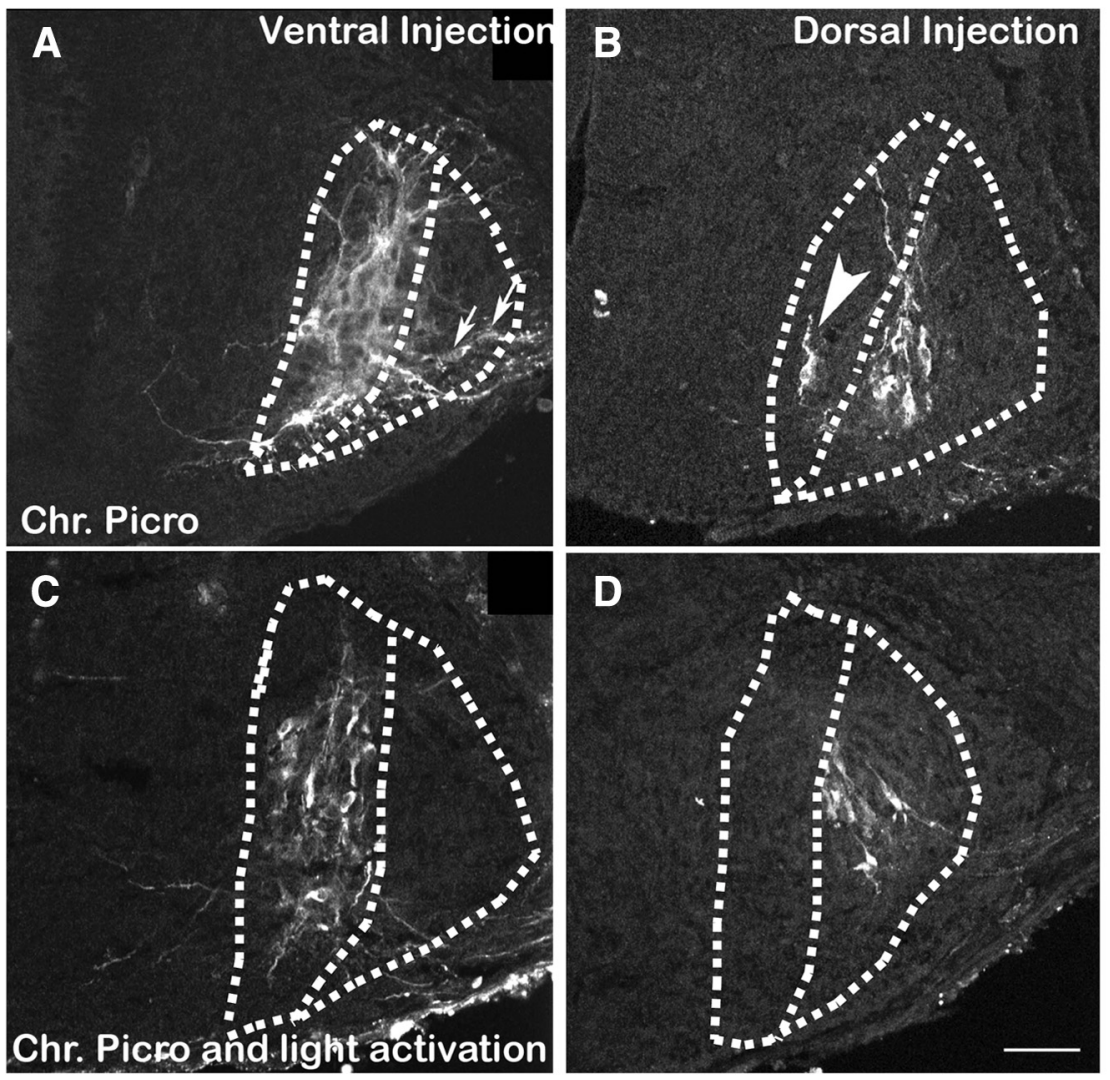

LMCI: Lim1+ Islet1-

LMCm: Islet1+ Lim1-

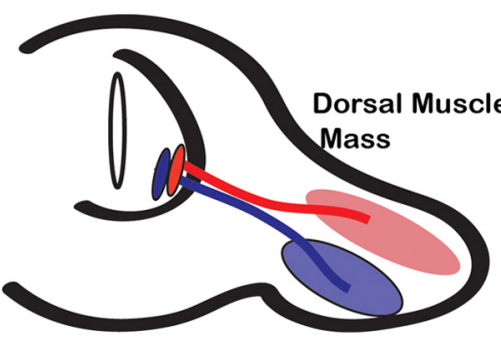

Ventral Muscle Mass

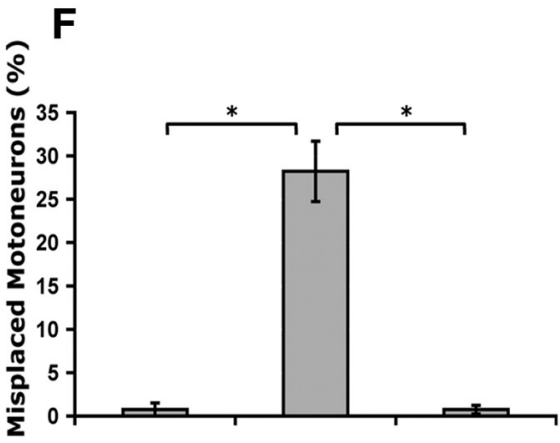

Control

Chr. Picro Chr. Picro and light activation

Figure 2. The location of HRP-labeled motoneuron somas at St 27 in chronic picrotoxin-treated embryos and in embryos treated with picrotoxin but activated via ChR2 at intervals of $40 \mathrm{~s}$. $A, B$, Sixteen micrometer cross sections of spinal cord, revealing the location of cell bodies immunolabeled with antibodies against HRP when ventral $(\boldsymbol{A})$ or dorsal $(\boldsymbol{B})$ nerve trunks where injected with HRP in chronic picrotoxin-treated embryos. White arrows and arrowhead highlight misplaced motoneurons. C, D, HRP immunostaining of $16 \mu \mathrm{m}$ spinal cord cross sections of embryos that underwent light activation by ChR2 in addition to chronic picrotoxin treatment. $\boldsymbol{E}$, Schematic representing dorsal and ventral projections of $L M C_{L}$ and $L M C_{M}$ motoneurons, respectively, as well as the transcription factor expression in the cell bodies of these motoneurons. $\boldsymbol{F}, \mathrm{A}$ bar graph depicting the number of misplaced motoneurons as a percentage of all labeled HRP-positive motoneurons per side in $16 \mu \mathrm{m}$ sections of the lumbar spinal cord (see Materials and Methods). Light activation by ChR2 in addition to chronic picrotoxin treatment prevented misplaced cell bodies that occurred in chronic picrotoxin-treated embryos. Light activation by ChR2 at control intervals reduced the large numbers of misplaced motoneurons observed in picrotoxin-treated embryos to control values, which are very low ( ${ }^{*} p<0.025$ ). Scale bar, $50 \mu \mathrm{m}$. Chr. Picro, Chronic picrotoxin treatment.

ing bursting activity both in ovo and in isolated cord preparations. Importantly, the bursts elicited by brief flashes of light were shown not to differ from the spontaneously generated bursts. In the present study, expression of eGFP was apparent at St 23 and was maintained until St 25 (Fig. 1D) when the embryos were assessed. Although the ChR2 was expressed on only one side of the spinal cord, the network- 
driven bursts arising from its activation were confirmed to propagate caudally into both sides of the lumbar cord.

At St 25, electroporated embryos that had been chronically treated with picrotoxin exhibited intermovement intervals of approximately twice the control value (Fig. $1 E$ ), whereas light activation restored the interval to the control value. We also found that, at least acutely, cords could be activated at approximately twice the normal frequency by ChR2 activation (Fig. $1 F$ ). In this experiment, ChR2-electroporated embryos that were not activated with light exhibited the same intermovement interval as nonelectroporated embryos, indicating that the electroporation of ChR2 itself did not alter the ability of cords to generate episodes of activity at the normal frequency. In summary, ChR2 electroporated into cervical spinal cord can be reliably activated with light to chronically elicit bursting activity at normal frequencies in the presence of chronic picrotoxin treatment. Thus, we were ready to activate picrotoxin-treated embryos with the normal frequency of bursting activity to determine whether altered bursting or $\mathrm{GABA}_{\mathrm{A}}$ signaling was necessary for proper pathfinding.

\section{Driving the normal frequency of activity with $\mathrm{ChR} 2$ in picrotoxin-treated embryos prevents $\mathrm{D}-\mathrm{V}$ motoneuron pathfinding errors assessed by motoneurons being located in inappropriate medial-lateral locations}

Normally, cell bodies of dorsally projecting motoneurons are located in the $\mathrm{LMC}_{\mathrm{L}}$, whereas cell bodies of ventrally projecting motoneurons are positioned in the $\mathrm{LMC}_{\mathrm{M}}$ (Landmesser, 1978; Lance-Jones and Landmesser, 1981a; Tsuchida et al., 1994) (Fig. $2 E)$. To assess misprojections, we injected HRP into the dorsal or ventral nerve trunks to label the cell bodies of motoneurons that had projected dorsally or ventrally. The cell bodies that were clearly mispositioned in the wrong half of the LMC (i.e., cell bodies of dorsally projecting motoneurons that were located in the $\mathrm{LMC}_{\mathrm{M}}$ and cell bodies of ventrally projecting motoneurons that were located in the $\mathrm{LMC}_{\mathrm{L}}$ ) were counted as misplaced motoneurons.

Chronic picrotoxin treatment between St 20 and St 30 perturbed normal guidance of motoneurons along the $\mathrm{D}-\mathrm{V}$ axis and resulted in motoneuron cell bodies that were misplaced in the medial-lateral axis of the cord (Hanson and Landmesser, 2004). In the current studies, embryos that were treated with chronic picrotoxin for shorter durations (St 20-27) also exhibited misplaced somas in the LMC at St 27, as shown in Figure $2 A, B$. We chose this stage to characterize since the migration of motoneuron somas to their appropriate medial-lateral locations is essentially complete by St 27 . When ventral nerve trunks were injected with HRP, the majority of somas that were retrogradely labeled were located in the proper $\mathrm{LMC}_{\mathrm{M}}$ position. However, in addition, misplaced cell bodies were also present in the $\mathrm{LMC}_{\mathrm{L}}(25 \pm 6.21 \%$ of all HRP-labeled somas) (Fig. 2A, white arrows). Similarly, when dorsal nerve trunks were injected with HRP, misplaced cell bodies were found in the $\mathrm{LMC}_{\mathrm{M}}(31 \pm 3.38 \%$ ) (Fig. $2 \mathrm{~B}$, white arrowhead). Thus, after picrotoxin treatment an approximately similar proportion of $\mathrm{LMC}_{\mathrm{L}}$ and $\mathrm{LMC}_{\mathrm{M}}$ motoneurons had misplaced somas, which we show in the next section are due to $\mathrm{D}-\mathrm{V}$ pathfinding errors. This observation is consistent with a previous study (Hanson and Landmesser, 2004) that showed that after retrograde labeling at St 30 from the sartorius or femorotibialis (dorsal muscles) or from the adductor (a ventral muscle) a similar proportion of misplaced motoneurons occurred for each pool after chronic picrotoxin treatment.

In the present study, we found that when the normal frequency of bursting activity was restored in picrotoxin-treated embryos by light activation by ChR2, motoneurons that were in
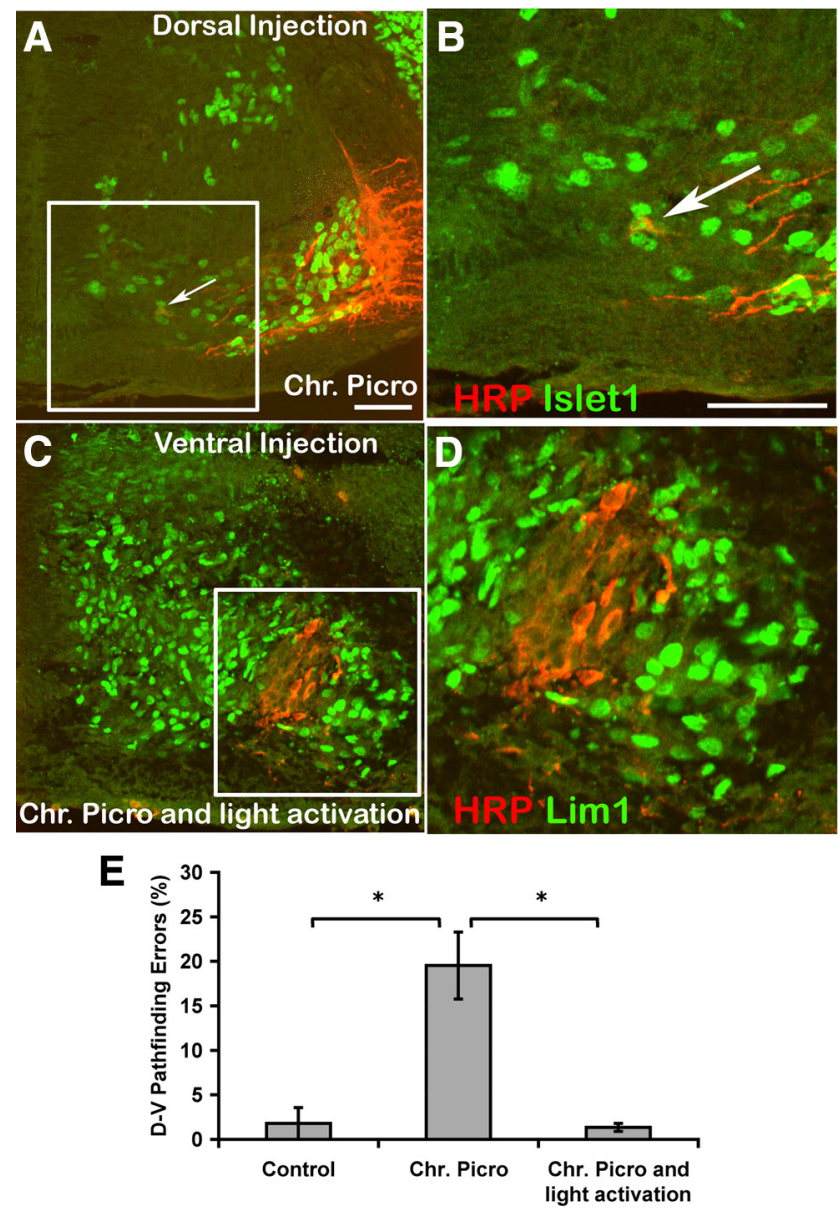

Figure 3. Characterization of the LIM homeodomain transcription factor code for misplaced motoneurons after chronic picrotoxin treatment. $A$, Low-magnification image of cell bodies of dorsally projecting motoneurons labeled with $\mathrm{HRP}$ (red) in a $16 \mu \mathrm{m}$ cross section of crural spinal cord of a picrotoxin-treated embryo. Islet1 immunoreactivity is depicted in green. A misplaced cell expressing Islet1, and therefore not an $\mathrm{LMC}_{\mathrm{L}}$ motoneuron, is highlighted with an arrow. $\boldsymbol{B}$, $2 \times$ magnification of the area within the box in $\boldsymbol{A}$. C, Low-magnification image of HRP (red)positive cell bodies of ventrally projecting motoneurons and Lim 1 immunoreactivity (green) in an embryo that underwent light activation by $\mathrm{ChR} 2$ in addition to acute picrotoxin treatment. $\boldsymbol{D}$, $2 \times$ magnification image of the area enclosed in the white box in $\boldsymbol{C}$. $\boldsymbol{E}$, The bar graph depicting the number of HRP-positive cells expressing the transcription factor incorrect for their D-V projections (Islet1-expressing motoneurons that projected dorsally and Lim1-expressing cells that projected ventrally) as a percentage of all HRP-labeled cells (see Materials and Methods) $\left({ }^{*} p<0.025\right)$. Light activation by $\mathrm{ChR} 2$ reduced the percentage of motoneurons that had made $D-V$ pathfinding errors from $\sim 20 \%$ to several percentage points similar to the control value. Scale bars: $\boldsymbol{A}, \boldsymbol{B}, 50 \mu \mathrm{m}$. Chr. Picro, Chronic picrotoxin treatment.

the inappropriate part of the motor column $\left(\mathrm{LMC}_{\mathrm{M}}\right.$ or $\left.\mathrm{LMC}_{\mathrm{L}}\right)$ were not observed (Fig. 2C,D). The number of misplaced motoneurons in control embryos, and in those treated chronically with picrotoxin as well as embryos, which were activated at control levels with ChR2 in addition to chronic picrotoxin treatment, were counted in serial frozen sections and expressed as a percentage of all retrogradely labeled cells (Fig. 2 F). Approximately $30 \%$ of the HRP-labeled cells had misplaced somas after picrotoxin treatment, but this was reduced to control levels (several percentage points) when the cords were simultaneously activated by light. This finding suggests that normal patterns of bursting activity and not $\mathrm{GABA}_{\mathrm{A}}$ receptor signaling are important for the normal pathfinding of motoneuron growth cones in the limb. However, it was also possible that the misplaced motoneurons might have been motoneurons that had migrated inappropriately rather than pathfinding errors. 
Picrotoxin causes pathfinding errors, which are rescued by activating cords at their normal bursting frequency

Motoneurons are generated in the ependymal layer and then migrate laterally to take their proper position in the LMC. Motoneurons destined for $\mathrm{LMC}_{\mathrm{M}}$ are born first (Hollyday and Hamburger, 1977). Later born motoneurons migrate through these cells to assume their position in the $\mathrm{LMC}_{\mathrm{L}}$. Thus, a point in time (typically St 24-25) exists when the two populations of motoneurons are intermixed (Hollyday and Hamburger, 1977) (K. V. Kastanenka and L. T. Landmesser, unpublished observations). Even though by St 27, when we quantified misplaced motoneurons, most motoneurons have assumed their proper positions in the LMC, it was possible that the misplaced motoneurons in the picrotoxin-treated embryos represented cell bodies that had not completed their migration or made errors in migration. To test for these possibilities, we injected dorsal or ventral nerve trunks with HRP and then determined whether misplaced motoneurons expressed Lim1 or Islet1, transcription factors which are expressed by nuclei of $\mathrm{LMC}_{\mathrm{L}}$ or $\mathrm{LMC}_{\mathrm{M}}$ motoneurons, respectively (Tsuchida et al., 1994). After a dorsal injection, most of the retrogradely labeled cells (Fig. 3A, red) were located in the lateral part of the LMC. However, some cells (an example is shown by the arrow) were located inappropriately in a medial location, and these cells expressed Islet1, the transcription factor characteristic of motoneurons located in the $\mathrm{LMC}_{\mathrm{M}}$. These cells did not express Lim1, which is expressed by all dorsally projecting neurons (data not shown). Similarly, cells that were observed in an inappropriate lateral location after HRP injection of the ventral nerve trunk ex-

pressed Lim1 and not Islet1. These could thus be defined as pathfinding errors. With picrotoxin and ChR2 activation, all cell bodies were appropriately positioned, and none expressed the transcription factor characteristic of the other class of motoneurons. Thus, all motoneurons labeled by a ventral injection were located medially, and none expressed the $\mathrm{LMC}_{\mathrm{L}}$ transcription factor Lim1 (Fig. 3C,D). Quantification of these results is shown in the bar graph in Figure 3E. Therefore, we can conclude that perturbation of signaling through $\mathrm{GABA}_{\mathrm{A}}$ receptors by chronic picrotoxin treatment cannot be responsible for $\mathrm{D}-\mathrm{V}$ path finding errors. Furthermore, the normal frequency of bursting activity plays a critical role in the guidance of motoneurons at this pathfinding decision.

\section{Maintenance of normal patterns of neural activity with light} activation by ChR2 maintains EphA4 levels on dorsally projecting motoneurons in picrotoxin-treated embryos During development, motoneurons make few pathfinding errors as they grow to their muscle targets (Lance-Jones and Landmesser, 1981a). En route to their targets, their growth cones encounter a variety of decision points, where they make divergent pathfinding choices. They navigate by sensing guidance cues in the environment with receptors present on their growth cones and actively respond to guidance molecules present in the mesenchyme of the limb (Lance-Jones and Landmesser, 1981b; Tosney and Landmesser, 1984; Huber et al., 2003). One such receptor molecule is EphA4, which is expressed more highly on dorsally than ventrally projecting motor axons. During outgrowth, EphA4-bearing axons are thought to be repelled from Ephrin A-rich ventral mesenchyme, and thus to be guided dorsally (Eberhart et al., 2002; Kania and Jessell, 2003).

To gain insight into the molecular mechanisms by which normal patterns of bursting activity are required for motoneurons to reach their proper targets along the D-V axis, EphA4 levels on distal axons were assessed in embryos chronically treated with picrotoxin. Picrotoxin treatment was previously shown to result in downregulation of EphA4 on the distal axons of dorsally projecting motoneurons compared with controls at St 25 (Hanson and Landmesser, 2004). This result was confirmed in the present experiments by immunostaining of limb cross sections at the $\mathrm{D}-\mathrm{V}$ bifurcation point with anti-EphA4 and neurofilament to label all 

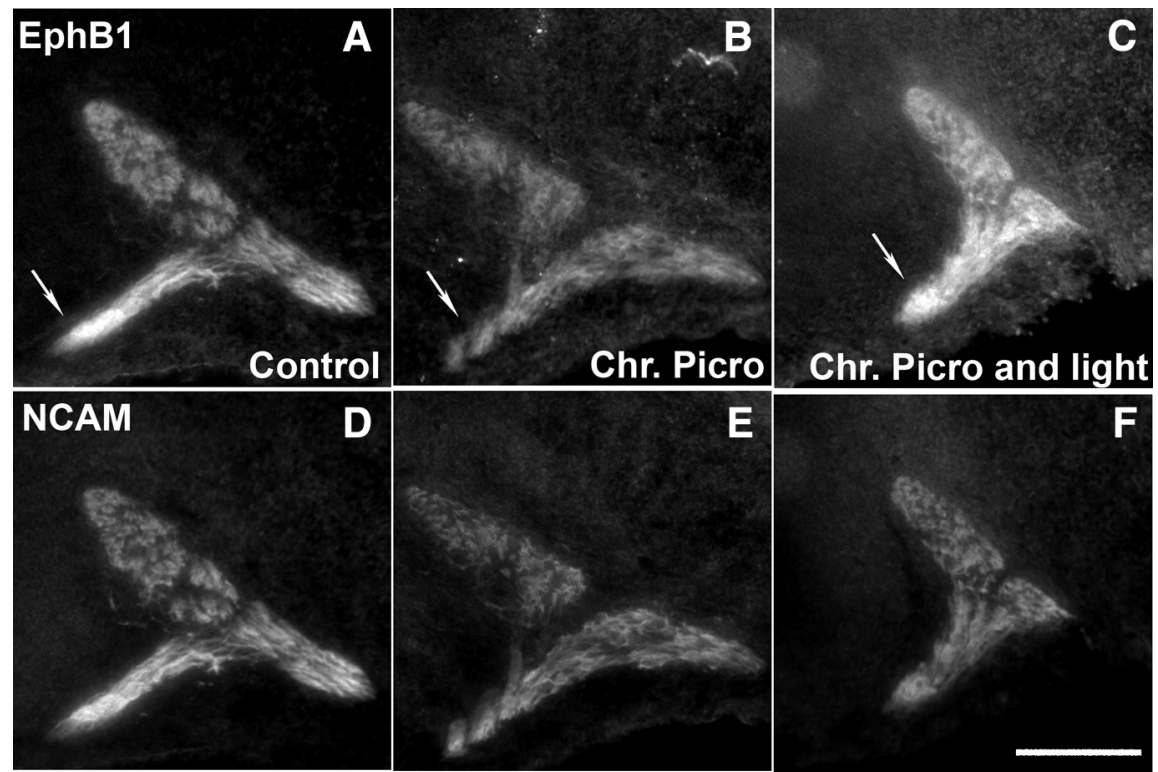

G

EphB1

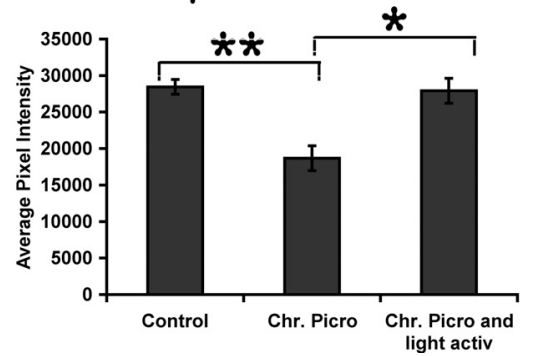

H

NCAM

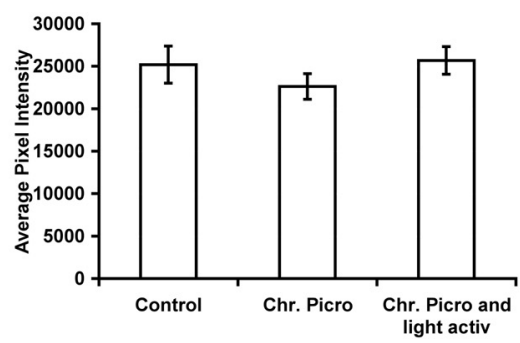

Figure 5. EphB1 expression on motoneuron axons distal to the $D-V$ choice point. $A-C$, Transverse $16 \mu \mathrm{m}$ sections of the limb showing EphB1 expression in control $(\boldsymbol{A})$, chronic picrotoxin $(\boldsymbol{B})$, and light activation by ChR2 in addition to chronic picrotoxin-treated ( $\boldsymbol{C}$ embryos. EphB1 is highly expressed on the ventral nerve trunk in control embryos ( $\boldsymbol{A}$, arrow). Chronic picrotoxin treatmentresults in downregulation of EphB1 ( $\boldsymbol{B}$, arrow; $\boldsymbol{G}$ ), while light activation by $\mathrm{ChR2}$ in addition to chronic picrotoxin treatment maintains EphB1 levels $(\boldsymbol{C}$, arrow; $\boldsymbol{G}$ ) similar to control embryos. $\boldsymbol{D}-\boldsymbol{F}$, NCAM expression visualized by immunostaining with a monoclonal antibody that recognizes all isoforms of NCAM in the same sections shown in $\boldsymbol{A}-\boldsymbol{C}$. $\boldsymbol{G}$, Mean pixel intensities of EphB1 immunostaining of the ventral nerve trunks are quantified and averaged for each condition. ${ }^{*} p<0.01$, ${ }^{* *} p<0.001$. $\boldsymbol{H}$, Levels of NCAM immunostaining on the ventral trunk did not differ from control for either of the treatments. Scale bar, $100 \mu \mathrm{m}$. Chr. Picro, Chronic picrotoxin treatment; activ, activation.

axons. EphA4 expression on the dorsal trunk was downregulated (Fig. $4 A, B$ arrows), while NF-M levels remained unchanged (Fig. $4 D, E)$. However, after light activation by ChR2 in addition to picrotoxin treatment, EphA4 protein was maintained at normal levels on dorsal trunks (Fig. 4C, arrow). The bar graph (Fig. 4G) shows that there was a statistically significant downregulation in the immunostaining for EphA4 in the dorsal nerve trunk with picrotoxin treatment and that driving activity at the control frequency and pattern in picrotoxin-treated embryos prevented this downregulation. Furthermore, EphA4 downregulation appeared to occur locally on distal axons since chronic picrotoxin treatment was previously shown not to affect EphA4 levels on cell bodies of motoneurons (Hanson and Landmesser, 2004). Our current results suggest that normal patterns of bursting activity are important for maintenance of EphA4 levels locally on axons.

EphB1 levels are also maintained on ventral nerve trunks of embryos, in which neural activity was driven at normal frequencies in the presence of picrotoxin Recently, another guidance molecule, EphB1, a receptor for Ephrin Bs was found to guide EphB1-expressing motoneurons ventrally (Luria et al., 2008) through repulsion from Ephrin B-rich dorsal mesenchyme. We therefore quantified EphB1 fluorescence levels on ventral nerve trunks of the limbs of control embryos, embryos chronically treated with picrotoxin and embryos that underwent light activation by ChR2 in addition to picrotoxin treatment. EphB1 levels were downregulated as a result of chronic picrotoxin treatment (Fig. 5A, B, arrows). Light activation by $\mathrm{ChR} 2$, however, maintained EphB1 levels similar to controls (Fig. 5A, C, arrows). In contrast, levels of NCAM immunostaining in the same regions of interest did not significantly differ between controls and the different treatments. These data are quantified in Figure $5 G$ and show that normal patterns of neural activity are necessary to maintain EphB1 levels, the guidance molecule necessary for proper projection of ventral axons. Thus, in summary, normal bursting activity, which was required for both proper dorsal and ventral pathfinding, also regulates the expression of guidance molecules on both dorsal and ventral nerve trunks.

\section{Normal patterns of neural activity maintain PSA levels on dorsally and ventrally projecting motoneurons in picrotoxin-treated embryos}

As motoneuron axons exit the spinal cord, they are tightly fasciculated due to expression of adhesion molecules such as L1/ NgCAM and NCAM. When motoneurons reach the plexus region at the base of the limb, they defasciculate due to upregulation of PSA, a carbohydrate that is added to NCAM (Tang et al., 1992, 1994). The highly negative charge on PSA and its large size act to decrease NCAM-NCAM and other cell-cell adhesive interactions, and results in defasciculation of PSA-bearing axons (Rutishauser and Landmesser, 1996). This enables growth cones on motor axons to more actively respond to guidance molecules such as EphA4 and EphB1 present in the limb. Removal of PSA with a specific enzyme, Endo-N, led to apparent D-V misprojection errors similar to those found in picrotoxin-treated embryos (Tang et al., 1992, 1994). Thus, PSA was previously shown to play a permissive role in the $\mathrm{D}-\mathrm{V}$ guidance of motoneuron axons.

Normally PSA is present on both dorsal and ventral nerve trunks with higher levels on the dorsal (Tang et al., 1992) (Fig. 6A, G). Chronic picrotoxin treatment resulted in downregulation of PSA levels on the distal axons of dorsally and ventrally projecting motoneurons, as well as on the somas (Hanson and Landmesser, 2004) (Fig. 6B,G), while NCAM levels remained similar (Fig. 6D,E). Light activation by ChR2 in addition to chronic picrotoxin treatment maintained PSA levels on both nerve trunks comparable to controls (Fig. $6 C, G)$. These data show that normal patterns of neural activity are necessary to maintain optimal levels of PSA, which allows 
axons to defasciculate and respond to guidance cues in the environment.

The expression of $\operatorname{Lim} 1$ is downregulated by St 27 on $\mathrm{LMC}_{\mathrm{L}}$ motoneurons but is rescued by driving bursting at the normal frequency with ChR2 activation

As motoneurons are born, they express the LIM homeodomain transcription factor Islet 1 , which is maintained in the motoneurons destined for the medial part of the LMC (Tsuchida et al., 1994). Motoneurons that settle in the lateral part of the LMC downregulate Islet 1 and upregulate Lim 1. This differential expression of the LIM homeodomain transcription factors is normally maintained even after the $\mathrm{D}-\mathrm{V}$ pathfinding is executed (as late as St 30). Our laboratory has previously shown that completely blocking spontaneous rhythmic activity with chronic combined strychnine and picrotoxin treatment between St 25 and St 30 resulted in the almost complete loss of Lim 1 expression in $\mathrm{LMC}_{\mathrm{L}}$ motoneurons and a strong downregulation of Islet 1 expression in $\mathrm{LMC}_{\mathrm{M}}$ motoneurons by St 30 (Hanson and Landmesser, 2004). To assess whether the more modest alterations in activity produced by slowing the frequency of bursts with picrotoxin between St 20 and St 25 would affect the expression of these LIM homeodomain transcription factors, their expression was quantified by immunolabeling at St 27. Lim 1 expression was downregulated in picrotoxin-treated embryos compared with controls (Fig. $7 A, B, G$ ), as assessed by quantifying the mean pixel intensity of $\mathrm{LMC}_{\mathrm{L}}$ motoneurons after immunostaining with an antibody against Lim 1 . These $\mathrm{LMC}_{\mathrm{L}}$ motoneurons are located lateral to the $\mathrm{LMC}_{\mathrm{M}}$ motoneurons (the $\mathrm{LMC}_{\mathrm{M}}$ is indicated by an asterisk), which do not express detectable levels of Lim 1 at this stage. The $\mathrm{LMC}_{\mathrm{L}} \mathrm{Lim}$ 1-positive cells can be seen between the arrowheads in Figure $7 A-C$. Interestingly, picrotoxin treatment downregulated Lim 1 expression selectively in motoneurons, since interneurons located dorsal and medial to the $\mathrm{LMC}_{\mathrm{M}}$ maintained Lim 1 expression similar to controls in picrotoxin-treated embryos (Fig. $7 A, B, G$ ). Driving the bursting activity at the control frequency with light activation by $\mathrm{ChR} 2$ in picrotoxin-treated embryos maintained Lim 1 expression at control levels (Fig. $7 C, G$ ). Although there was a trend toward increased Islet 1 expression in $\mathrm{LMC}_{\mathrm{M}}$ motoneurons (Fig. $7 D, E$ ) in picrotoxin-treated embryos (Fig. $7 D-F$, Islet 1-positive cells between arrowheads in the $\mathrm{LMC}_{\mathrm{M}}$; $\mathrm{LMC}_{\mathrm{L}}$ is indicated by asterisk), this did not reach statistical significance (Fig. $7 \mathrm{H}$ ). Islet 1 expression was also not significantly different from controls in embryos exposed to combined light activation by $\mathrm{ChR} 2$ and picrotoxin treatment (Fig. $7 \mathrm{~F}, H$ ).

Together, these data show that Lim 1 expression in lumbar motoneurons is sensitive to modest alterations in the frequency of bursting activity and that it is significantly downregulated by St
27. While this is too late to have affected the $\mathrm{D}-\mathrm{V}$ pathfinding choices, later attributes of $\mathrm{LMC}_{\mathrm{L}}$ motoneurons that are controlled by Lim 1 could be affected. The insensitivity of Lim 1 expression to alterations in activity in lumbar interneurons, many of which are involved in generating the locomotor pattern, is intriguing and suggests complex differential regulation of Lim 1 in different classes of spinal neurons. While Islet 1 expression was not altered at this stage, it might be at later developmental stages that were not assessed in this study. The total number of $\mathrm{LMC}_{\mathrm{L}}$ and $\mathrm{LMC}_{\mathrm{M}}$ motoneurons, assessed by immunostaining with an antibody that recognizes Islet 1 and Islet 2, and which labels both populations of neurons was not altered by picrotoxin treatment $(187 \pm 4.8$ cells per sections for controls vs $192 \pm 6.3$ cells per section for picrotoxin-treated embryos).

\section{Discussion}

Spontaneous waves of neural activity are required for proper pathfinding of motoneurons during development (Hanson and Landmesser, 2004, 2006). We showed here that alteration in the precise frequency of activity and not perturbation of $\mathrm{GABA}_{\mathrm{A}}$ signaling was responsible for the observed $\mathrm{D}-\mathrm{V}$ misprojections of 

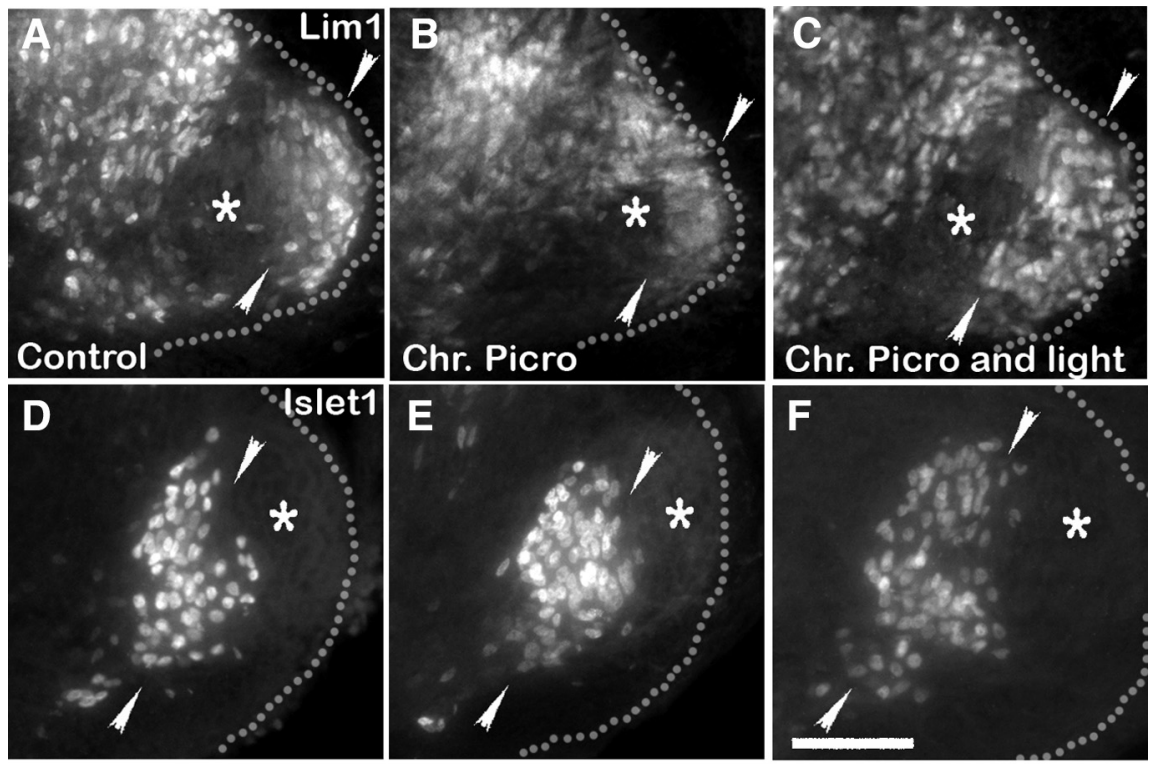

G Control Chr. Picro

Chr. Picro and light activ

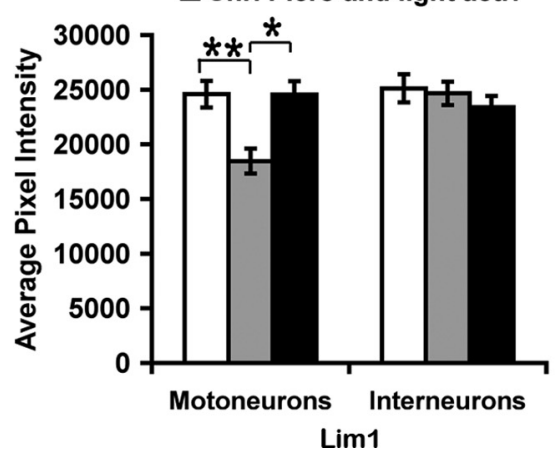

H

$\square$ Contro

Chr. Picro

Chr. Picro and light activ

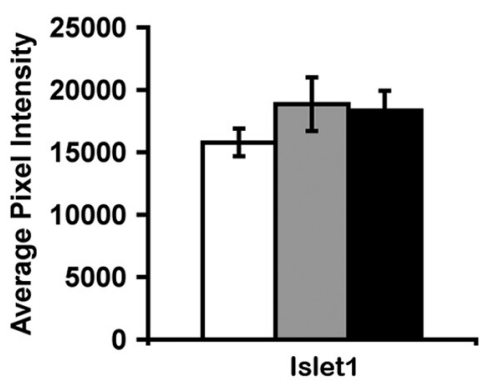

Islet1

Figure 7. Lim 1 and Islet 1 expression on motoneurons in the lumbar spinal cord in control, picrotoxin-treated, and combined picrotoxin/light activated embryos. $\boldsymbol{A}-\boldsymbol{C}$, Transverse sections of the lumbar spinal cord showing Lim 1 expression in $L_{M} C_{L}$ mo- $^{-}$ toneurons ( $L M C_{L}$ motoneurons are shown between arrowheads, lateral to $L M C_{M}$ marked by asterisks) and in interneurons (dorsal and medial to $L M C)$. $\boldsymbol{D}-\boldsymbol{F}$, Islet 1 expression in $L M C_{M}$ motoneurons $\left(L_{M} C_{M}\right.$ motoneurons are shown between arrowheads, while $\mathrm{LMC}_{\mathrm{L}}$ is marked by asterisks). The most lateral edge of the spinal cord is outlined. Dorsal is up, medial is left. Chronic picrotoxin treatment resulted in downregulation of Lim 1 in $L M C$ motoneurons but not in interneurons located dorsal and medial to the $L M C_{M}$ $(\boldsymbol{A}, \boldsymbol{B})$. Light activation by ChR2 maintained control levels of Lim 1 in motoneurons (C). D-F, Islet 1 expression was not statistically different between controls $(\boldsymbol{D})$, chronic picrotoxin-treated embryos $(\boldsymbol{E})$ or in picrotoxin-treated embryos whose bursting activity was maintained at control frequency with light activation by $\operatorname{ChR2}(\boldsymbol{F}), \boldsymbol{G}, \boldsymbol{H}$, Bar graphs showing quantification of average pixel intensities for $\operatorname{Lim} 1(\boldsymbol{G})$ and Islet $1(\boldsymbol{H})\left({ }^{*} p<0.01\right)$. Calibration: $50 \mu \mathrm{m}$. Chr. Picro, Chronic picrotoxin treatment; activ, activation.
In Xenopus, the frequency of neural activity differs between subclasses of spinal neurons and regulates their neurotransmitter phenotypes (Borodinsky et al., 2004). In the chick and mouse, however, waves of activity appear to activate most motoneurons and interneurons with the same frequency (Milner and Landmesser, 1999, Hanson and Landmesser, 2003), a finding recently confirmed for motoneurons via two-photon imaging of $\mathrm{Ca}^{2+}$ transients (Wang et al., 2009). Thus, in these species, the phenotypes of subclasses of spinal neurons cannot be specified by different frequencies of activity. However, a recent study showed that early in development, zebrafish narrowminded mutant embryos, which lack motor activity, exhibited defects in motor axon pathfinding. Blocking depolarizing neural activity with pharmacological agents similarly resulted in pathfinding errors, while restoring depolarizing drive restored normal axonal guidance (Menelaou et al., 2008).

The mechanism by which neural activity regulates axonal pathfinding is currently unknown. Many groups have characterized the responses of axons to guidance cues in culture (for review, see Gomez and Spitzer, 2000; Gomez and Zheng, 2006; Zheng and Poo, 2007), and some have shown that activity can influence the response of an axon to guidance cues (Ming et al., 2001). However, only in vivo can one study how activity affects motoneurons when they are interacting with the complex arrays of their natural guidance cues as well as other signaling molecules that may be activated as a result of activity. For example, during bursts motoneurons are exposed to a variety of neurotransmitters, including acetylcholine, GABA, and glycine, which establish the bursting rhythm and also initiate signaling downstream of their receptors. We showed here that activating motor circuits motoneurons when bursting frequency was slowed with picrotoxin. When picrotoxin-treated embryos were stimulated with light to activate electroporated ChR2 at normal frequencies, the motoneuron pathfinding errors caused by picrotoxin treatment were prevented. In addition, the expression of EphA4, EphB1, and PSA on NCAM were maintained at normal levels in these embryos, whereas they were downregulated in picrotoxin-treated animals.

In the avian and mammalian visual systems, patterned spontaneous activity in the form of retinal waves has been shown to be important for refining visual projections in the lateral geniculate nucleus, superior colliculus, and visual cortex (for review, see Huberman et al., 2008). However, the effect of waves on the initial pathfinding of retinal ganglion cells has not been assessed, and initial pathfinding has long been considered to be activity independent (Katz and Shatz, 1996; Erzurumlu and Kind, 2001). with light via ChR2 while $\mathrm{GABA}_{\mathrm{A}}$ receptors were blocked with picrotoxin prevented $\mathrm{D}-\mathrm{V}$ pathfinding errors, indicating the frequency of bursts and not $\mathrm{GABA}_{\mathrm{A}}$ signaling as the critical variable that enables proper $\mathrm{D}-\mathrm{V}$ pathfinding. Supporting this hypothesis, Wang et al. (2009) recently showed that picrotoxin increased the intervals between bursting episodes and the ensuing calcium transients without altering their amplitude or duration.

Among the guidance molecules involved in this pathfinding decision are EphA4 and EphB1, which regulate the appropriate pathfinding of dorsally and ventrally projecting axons, respectively. We found a significant decrease in the expression of EphA4 and EphB1 proteins (Eberhart et al., 2002; Kania and Jessell, 2003; Luria et al., 2008) on distal axons after chronic picrotoxin treatment. However, normal levels were maintained when the frequency of bursting activity was driven at normal levels in picrotoxin-treated embryos. Expression of other molecules not implicated in the D-V pathfinding decision, such as NCAM, neu- 
rofilament, and CRYP $\alpha$, were not altered by picrotoxin treatments (Hanson and Landmesser, 2004; our results). Thus, the normal pattern of spontaneous neural activity and not $\mathrm{GABA}_{\mathrm{A}}$ signaling is necessary for maintenance of EphA4 and EphB1 levels.

Decreases in EphA4 and EphB1 expression in picrotoxintreated embryos could be due to a variety of mechanisms, one being decreased synthesis of new protein. However, EphA4 mRNA levels in the soma were comparable in St 24 chronic picrotoxin-treated and control embryos (Hanson and Landmesser, 2004), suggesting that transcription of EphA4 had not been affected. Translation, at least in the soma, also seemed not to be affected since EphA4 protein levels in the LMC were similar in St 24 control and picrotoxin-treated embryos. However, both that study and the present one observed downregulation of EphA4 protein levels on distal axons by picrotoxin treatment. Growth cones contain protein synthesis and degradation machinery, and are capable of local protein synthesis (Campbell and Holt, 2001). Axons contain ribosomal proteins, translational initiation factors, rRNA, and the machinery necessary for export of membrane proteins (for review, see Yoon et al., 2009). Such local protein synthesis might maintain EphA4 levels (for example, see Brittis et al., 2002) and be sensitive to the frequency of bursts or calcium transients in the growth cone. Alternatively, there may be changes in EphA4 and EphB1 receptor insertion, or removal and degradation from the plasma membrane of distal axons and growth cones (for review, see O'Donnell et al., 2009). Although such processes have not yet been shown to be activity dependent, the insertion and removal of neurotransmitter receptors from the plasma membrane of dendrites is sensitive to activity (Kessels and Malinow, 2009).

The transcription factors Lim1 and Islet1 were shown to regulate EphA4 and EphB1 expression on LMC motoneurons, and thus their dorsal and ventral projections, respectively (Kania et al., 2000; Kania and Jessell, 2003; Luria et al., 2008). Therefore, bursting activity might regulate EphA4 and EphB1 levels through changes in Lim1 and Islet1 expression, respectively. Complete blockade of activity from St 25 to St 30 caused a dramatic downregulation of Lim 1 by St 30 and a significant downregulation of Islet 1 as well. However, at St $26 \mathrm{Lim} 1$ and Islet 1 levels did not differ from controls (Hanson and Landmesser, 2004), suggesting that reduction in the expression of these transcription factors could not have caused the D-V pathfinding errors. In this study, we also obtained evidence that Lim1 expression was sensitive to activity and was significantly downregulated in St 27 motoneurons after picrotoxin treatment. This appeared to be selective for motoneurons since Lim 1 levels were not altered in interneurons in the same sections. Similarly, slowing activity by picrotoxin did not cause significant downregulation of Islet 1. Importantly, the normal expression of Lim 1 was maintained in picrotoxin-treated embryos that were activated at normal frequencies with ChR2. Thus, the expression of Lim 1 is sensitive to the precise frequency of spontaneous bursting activity, and alterations in Lim 1 expression could affect any aspects of motoneuron development controlled by Lim 1 at later developmental stages.

The expression of PSA was also downregulated in chronic picrotoxin-treated embryos, but was maintained by light activation by ChR2. Reduced axon-axon adhesive interactions caused by the high negative charge and large size of PSA (Johnson et al., 2004) facilitates defasciculation of motor axons at the D-V choice point (Tang et al., 1992, 1994). Chronic picrotoxin treatment did in fact increase the degree of fasciculation at this decision point (Hanson and Landmesser, 2004), consistent with a downregula- tion of PSA. Furthermore, enzymatic removal of PSA with EndoN resulted in increased fasciculation and led to D-V pathfinding errors (Tang et al., 1992) similar to those in picrotoxintreated embryos. Since calcium influx caused by neural activity can regulate the proper expression of PSA during development (Fredette et al., 1993; Rafuse and Landmesser, 1996), calcium might affect the synthesis of polysialyltransferases that add PSA to NCAM, influence activity of the enzymes, or modulate insertion or degradation of polysialylated NCAM from the plasma membrane (Scheidegger et al., 1994) (for review, see Kiss and Rougon, 1997). Alternatively, PSA might be downregulated by cleavage of the PSA-bearing extracellular domain of NCAM by proteases (Hinkle et al., 2006). Together, these results suggest that whereas the downregulation of EphA4 and EphB1 may contribute to the observed D-V pathfinding errors, normal PSA expression is also required for the axons to respond to these guidance cues. Other molecules, not studied, could also be sensitive to activity and contribute to the observed pathfinding errors. It is nevertheless intriguing that three different molecules required for effective $\mathrm{D}-\mathrm{V}$ pathfinding are all downregulated when the frequency of spontaneous activity is decreased, and it will be interesting to determine the cellular mechanisms underlying this coordinate regulation.

In conclusion, this study shows that in intact chick embryos, normal patterns of spontaneous neural activity, and not signaling through $\mathrm{GABA}_{\mathrm{A}}$ receptors are critical for proper $\mathrm{D}-\mathrm{V}$ pathfinding and $\mathrm{D}-\mathrm{V}$ guidance molecule expression. A major challenge will be to identify the downstream effectors, which appear to be highly sensitive to the precise frequency of bursting activity and associated calcium transients. Finally, this study demonstrates that ChR2 is not only useful in acutely activating neuronal circuits ( $\mathrm{Li}$ et al., 2005) but can also be used to influence activity-dependent pathfinding and connectivity, and could thus have considerable translational applications in circuit remodeling to restore function after injury- or disease-mediated alterations.

\section{References}

Borodinsky LN, Root CM, Cronin JA, Sann SB, Gu X, Spitzer NC (2004) Activity-dependent homeostatic specification of transmitter expression in embryonic neurons. Nature 429:523-530.

Brittis PA, Lu Q, Flanagan JG (2002) Axonal protein synthesis provides a mechanism for localized regulation at an intermediate target. Cell 110:223-235.

Campbell DS, Holt CE (2001) Chemotropic responses of retinal growth cones mediated by rapid local protein synthesis and degradation. Neuron 32:1013-1026.

Chub N, O’Donovan MJ (1998) Blockade and recovery of spontaneous rhythmic activity after application of neurotransmitter antagonists to spinal networks of the chick embryo. J Neurosci 18:294-306.

Eberhart J, Swartz ME, Koblar SA, Pasquale EB, Krull CE (2002) EphA4 constitutes a population-specific guidance cue for motor neurons. Dev Biol 247:89-101.

Erzurumlu RS, Kind PC (2001) Neural activity: sculptor of "barrels" in the neocortex. Trends Neurosci 24:589-595.

Fredette B, Rutishauser U, Landmesser L (1993) Regulation and activitydependence of N-cadherin, NCAM isoforms, and polysialic acid on chick myotubes during development. J Cell Biol 123:1867-1888.

Gomez TM, Spitzer NC (2000) Regulation of growth cone behavior by calcium: new dynamics to earlier perspectives. J Neurobiol 44:174-183.

Gomez TM, Zheng JQ (2006) The molecular basis for calcium-dependent axon pathfinding. Nat Rev Neurosci 7:115-125.

Gonzalez-Islas C, Wenner P (2006) Spontaneous network activity in the embryonic spinal cord regulates AMPAergic and GABAergic synaptic strength. Neuron 49:563-575.

Hanson MG, Landmesser LT (2003) Characterization of the circuits that generate spontaneous episodes of activity in the early embryonic spinal cord. J Neurosci 23:587-600. 
Hanson MG, Landmesser LT (2004) Normal patterns of spontaneous activity are required for correct motor axon guidance and the expression of specific guidance molecules. Neuron 43:687-701.

Hanson MG, Landmesser LT (2006) Increasing the frequency of spontaneous rhythmic activity disrupts pool-specific axon fasciculation and pathfinding of embryonic spinal motoneurons. J Neurosci 26:12769-12780.

Hinkle CL, Diestel S, Lieberman J, Maness PF (2006) Metalloproteaseinduced ectodomain shedding of neural cell adhesion molecule (NCAM). J Neurobiol 66:1378-1395.

Hollyday M, Hamburger V (1977) An autoradiographic study of the formation of the lateral motor column in the chick embryo. Brain Res 132:197-208.

Huber AB, Kolodkin AL, Ginty DD, Cloutier JF (2003) Signaling at the growth cone: ligand-receptor complexes and the control of axon growth and guidance. Annu Rev Neurosci 26:509-563.

Huberman AD, Feller MB, Chapman B (2008) Mechanisms underlying development of visual maps and receptive fields. Annu Rev Neurosci 31:479-509.

Johnson CP, Fujimoto I, Rutishauser U, Leckband DE (2005) Direct evidence that neural cell adhesion molecule (NCAM) polysialylation increases intermembrane repulsion and abrogates adhesion. J Biol Chem 280:137-145.

Kania A, Jessell TM (2003) Topographic motor projections in the limb imposed by LIM homeodomain protein regulation of ephrin-A:EphA interactions. Neuron 38:581-596.

Kania A, Johnson RL, Jessell TM (2000) Coordinate roles for LIM homeobox genes in directing the dorsoventral trajectory of motor axons in the vertebrate limb. Cell 102:161-173.

Katz LC, Shatz CJ (1996) Synaptic activity and the construction of cortical circuits. Science 274:1133-1138.

Kessels HW, Malinow R (2009) Synaptic AMPA receptor plasticity and behavior. Neuron 61:340-350.

Kiss JZ, Rougon G (1997) Cell biology of polysialic acid. Curr Opin Neurobiol 7:640-646.

Lance-Jones C, Landmesser LT (1981a) Pathway selection by chick lumbosacral motoneurons during normal development. Proc R Soc Lond 214:1-18.

Lance-Jones C, Landmesser LT (1981b) Pathway selection by embryonic chick lumbosacral motoneurons in an experimentally altered environment. Proc R Soc Lond 214:19-52.

Landmesser L (1978) The distribution of motoneurons supplying chick hind limb muscles. J Physiol 284:371-389.

Li X, Gutierrez DV, Hanson MG, Han J, Mark MD, Chiel H, Hegemann P, Landmesser LT, Herlitze S (2005) Fast noninvasive activation and inhibition of neural and network activity by vertebrate rhodopsin and green algae channelrhodopsin. Proc Natl Acad Sci U S A 102:17816-17821.

Luria V, Krawchuk D, Jessell TM, Laufer E, Kania A (2008) Specification of motor axon trajectory by ephrin-B:EphB signaling: symmetrical control of axonal patterning in the developing limb. Neuron 60:1039-1053.

Menelaou E, Husbands EE, Pollet RG, Coutts CA, Ali DW, Svoboda KR
(2008) Embryonic motor activity and implications for regulating motoneuron axonal pathfinding in zebrafish. Eur J Neurosci 28:1080-1096.

Milner LD, Landmesser LT (1999) Cholinergic and GABAergic inputs drive patterned spontaneous motoneuron activity before target contact. J Neurosci 19:3007-3022.

Ming G, Henley J, Tessier-Lavigne M, Song H, Poo M (2001) Electrical activity modulates growth cone guidance by diffusible factors. Neuron 29:441-452.

Momose-Sato Y, Mochida H, Kinoshita M (2009) Origin of the earliest correlated neuronal activity in the chick embryo revealed by optical imaging with voltage-sensitive dyes. Eur J Neurosci 29:1-13.

O'Donnell M, Chance RK, Bashaw GJ (2009) Axon growth and guidance: receptor regulation and signal transduction. Annu Rev Neurosci 32:383-412.

O’Donovan MJ, Bonnot A, Wenner P, Mentis GZ (2005) Calcium imaging of network function in the developing spinal cord. Cell Calcium $37: 443-450$.

Owens DF, Kriegstein AR (2002) Is there more to GABA than synaptic inhibition? Nat Rev Neurosci 3:715-727.

Rafuse VF, Landmesser L (1996) Contractile activity regulates isoform expression and polysialylation of NCAM in cultured myotubes: involvement of $\mathrm{Ca} 2+$ and protein kinase C. J Cell Biol 132:969-983.

Represa A, Ben-Ari Y (2005) Trophic actions of GABA on neuronal development. Trends Neurosci 28:278-283.

Rutishauser U, Landmesser L (1996) Polysialic acid in the vertebrate nervous system: a promoter of plasticity in cell-cell interactions. Trends Neurosci 19:422-427.

Scheidegger P, Papay J, Zuber C, Lackie PM, Roth J (1994) Cellular site of synthesis and dynamics of cell surface re-expression of polysialic acid of the neural cell adhesion molecule. Eur J Biochem 225:1097-1103.

Tang J, Landmesser L, Rutishauser U (1992) Polysialic acid influences specific pathfinding by avian motoneurons. Neuron 8:1031-1044.

Tang J, Rutishauser U, Landmesser L (1994) Polysialic acid regulates growth cone behavior during sorting of motor axons in the plexus region. Neuron 13:405-414.

Tosney KW, Landmesser LT (1984) Pattern and specificity of axonal outgrowth following varying degrees of chick limb bud ablation. J Neurosci 4:2518-2527.

Tsuchida T, Ensini M, Morton SB, Baldassare M, Edlund T, Jessell TM, Pfaff SL (1994) Topographic organization of embryonic motor neurons defined by expression of LIM homeobox genes. Cell 79:957-970.

Wang S, Polo-Parada L, Landmesser LT (2009) Characterization of rhythmic $\mathrm{Ca}^{2+}$ transients in early embryonic chick motoneurons: $\mathrm{Ca}^{2+}$ sources and effects of altered activation of transmitter receptors. J Neurosci 29:15232-15244.

Yoon BC, Zivraj KH, Holt CE (2009) Local translation and mRNA trafficking in axon pathfinding. Results Probl Cell Differ 48:269-288.

Zheng JQ, Poo MM (2007) Calcium signaling in neuronal motility. Annu Rev Cell Dev Biol 23:375-404. 